\title{
LETTERS
}

\section{Rigorous policies ensure integrity of NLM literature databases}

We read with interest the article titled "How predatory journals leak into PubMed," by Dr. Manca and colleagues published in CMAJ. ${ }^{1}$ We thank the authors for their interest in PubMed and PubMed Central and provide clarification on which journals the US National Library of Medicine has selected for inclusion in these databases.

The premise of the article by Manca and colleagues is based on 2 of their previous studies, in which they suggest that a high number of "predatory" journals are accepted for indexing in PubMed or archiving in PubMed Central, and that the National Library of Medicine should "raise the bar for journal inclusion."

However, Manca and colleagues have mistakenly characterized these journals as being included in PubMed and PubMed Central by conflating the appearance of 1 or more individual journal articles that are included in PubMed Central to support the public access policies of research funders, ${ }^{2,3}$ with the inclusion of articles from an accepted journal. A journal is considered "accepted" and added to PubMed only if it has been formally assessed and recommended for indexing in MEDLINE or archiving in PubMed Central.
Moreover, the authors make several incorrect statements about PubMed and National Library of Medicine policies, most notably regarding journal selection criteria for PubMed Central. In fact, journals that apply to be in PubMed Central undergo a rigorous assessment of scientific and editorial quality, ${ }^{4}$ and the same assessment considerations are used to re-evaluate previously accepted journals. ${ }^{5}$ In addition, the National Library of Medicine reviews publishers of PubMed Central and MEDLINE journals for ongoing conformance with publishing guidelines and best practices. ${ }^{6}$

The National Library of Medicine is committed to the integrity of its literature databases and continues to develop its selection processes in response to changes in the scholarly publishing environment.

\section{Lauren Topper PhD}

PubMed Central journal review program coordinator, US National Library of Medicine, Bethesda, Md.

\section{Jennifer Marill MA MS}

Chief, Technical Services Division, US

National Library of Medicine, Bethesda, Md.

\section{Christopher Kelly MBA}

Program specialist, PubMed Central, US

National Library of Medicine, Bethesda, Md.

\section{Kathryn Funk MLIS}

Program manager, PubMed Central, US

National Library of Medicine, Bethesda, Md.
Cite as: CMAJ 2019 March 11;191:E289. doi: $10.1503 / \mathrm{cmaj} .71602$

\section{References}

1. Manca A, Moher D, Cugusi L, et al. How predatory journals leak into PubMed. CMAJ 2018;190: E1042-5.

2. How papers get into PMC. Bethesda (MD): National Center for Biotechnology Information, U.S. National Library of Medicine; updated 2015 Jan. 7. Available: www.ncbi.nlm.nih.gov/pmc/about/ submission-methods/ (accessed 2018 Nov. 7).

3. $P M C$ and research funder policies. Bethesda (MD): National Center for Biotechnology Information, U.S. National Library of Medicine; updated 2018 Sept. 12. Available: www.ncbi.nlm.nih.gov/pmc/ about/public-access/ (accessed 2018 Nov. 7).

4. Journal selection for PMC. Bethesda (MD): National Center for Biotechnology Information, U.S. National Library of Medicine; updated 2018 June 19. Available: www.ncbi.nlm.nih.gov/pmc/ pub/journalselect/ (accessed 2018 Nov. 8).

5. PMC policies - scientific, editorial, and technical standards: reevaluation. Bethesda (MD): National Center for Biotechnology Information, U.S. National Library of Medicine; updated 2018 Sept. 11. Available: www.ncbi.nlm.nih.gov/pmc/about/ guidelines/\#standards (accessed 2018 Nov. 8).

6. Marill JL. Journal selection at the National Library of Medicine: a new process for challenging times. Technicalities 2016;36:1-5. Available: www.nlm.nih. gov/pubs/staffpubs/lo/TECH_V36_N4_JulAug16_ Marill.pdf (accessed 2018 Nov. 6).

Competing interests: The authors are employed by the US National Library of Medicine, the producer of the MEDLINE database, PubMed and PubMed Central. This work was supported by the Intramural Research Program of the National Library of Medicine, National Institutes of Health. 